\title{
Goitrogenic and Antithyroid Potential of Green Tea Of Indian Origin
}

\author{
Amar Kumar Chandra ${ }^{1}$, Neela De ${ }^{2}$
}

\begin{abstract}
Polyphenolic flavonoids, specially catechins are major constituents of tea. Antithyroidal and goitrogenic effect of flavonoids have been reported however such effects of green tea on thyroid physiology has not been explored earlier. Green tea is derived from the tea leaves of Camellia sinensis and widely consumed globally. The green tea extracts(GTE) at different concentrations ( $1.25 \mathrm{~g} \%$ a" 5 cups of tea/ day; $2.5 \mathrm{~g} \%$ a" 10 cups of tea/ day and $5.0 \mathrm{~g} \% \mathrm{a}$ " 20 cups of tea/ day) were orally fed to male rats for 30 days. Similarly, pure catechin was administered orally to male albino rats for 30 days at doses of 25,50 and $100 \mathrm{mg} / \mathrm{kg}$ body weight that are equivalent to above doses of green tea extract in terms of its total catechin content and the morphological and functional changes of the thyroid have been investigated. The overall results reveal that oral administration of green tea extract at $2.5 \mathrm{~g} \%$ and $5.0 \mathrm{~g} \%$ concentrations for 30 days changed the morphology and histology resembling hypertrophy of thyroid follicles with differential colloid sizes as found in hypothyroid due to environment influences associated with significant inhibited activities of thyroid peroxidase(TPO) and 5' monodeiodinase (5' DI1) with elevated $\mathrm{Na}+, \mathrm{K}+$ ATPase and concomitant decrease in serum thyroxine (T4), triiodothyronine (T3) and increase in serum thyrotropin (TSH) levels developing a state of absolute biochemical hypothyroidism. All these suggest that catechin present in green tea has the antithyroidal as well as goitrogenic potential and its regular consumption at relatively high doses pose a threat to the functioning of thyroid.
\end{abstract}

Key words : Green tea, Catechin, Thyroid peroxidase, $\mathrm{Na}+, \mathrm{K}+-\mathrm{ATPase}, 5^{\prime}$ Deiodinase I, Thyroid, Goiter, Antithyroidal activity, Goitrogens.

Bangladesh Soc Physiol. 2014, December; 9(2): 105-116 For Authors Affiliation, see end of text.

http://www.banglajol.info/index.php/JBSP

\section{Introduction}

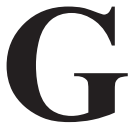

reen tea is derived from the tea leaves of Camellia sinensis. It is rich in flavonoids and has the highest quantity of tea catechins that are chemically defined as flavan-3-ols. In general, green tea contains about $30 \% \mathrm{w} / \mathrm{w}$ of catechins in the dry leaves. The major catechins, which are found in abundant proportion are (-) EGCG - (Epigallo catechin

Received October 2014; Accepted November 2014 gallate), (-) EGC - (Epigallo catechin), (-) EC (Epicatechin) and (-) ECG - (Epicatechin gallate) with (-) CG-Catechin gallate. Other compounds obtainable in tea are the flavonols (quercetin, kaempferol, myricitin and rutin); caffeine, phenolic acids, theanine and flavour compounds ${ }^{1}$. Green tea is commonly consumed in China, Japan and Eastern Asia, The intake of catechins can be expected to be higher in the Asiatic countries and the health effects of green tea may be more apparent when examined in the Asian communities ${ }^{2}$.Tea is a source of a wide 
range of phytochemicals that are digested, absorbed and metabolized by the body and tea constituents exert their effects at the cellular level $^{3}$. Epidemiologic evidence provides a convincing argument that polyphenolic antioxidants present in green can reduce several chronic diseases, especially cardiovascular disease and cancer ${ }^{4}$.

Despite its enormous usefulness and potential health benefits, flavonoids emerge as phytochemicals of great concern due to their antithyroidal and goitrogenic effect. It has previously been reported that the consumption of flavonoids and some phenolic acids by experimental animals induced enlargement and histological changes in the thyroid gland ${ }^{5-9}$. Studies on effects of tea extracts on thyroid physiology are not available though it is used as whole beverage rather taking any single component of it, so this is very plausible to investigate the effect of total green tea extract on rats. The effects of green tea consumption at different doses on the thyroid physiology have been explored to understand the pathophysiology of its goitrogenic potential in euthyroid rats. For the purpose dose or concentration dependent effects of total GTEs without any specific purification of possible candidate compounds on thyroid gland architecture, thyroid peroxidase (TPO), 5'deiodinase I (5'-DI) and sodium-potassium adenosine triphosphatase $\left(\mathrm{Na}^{+}, \mathrm{K}^{+}\right.$ATPase) activities, and serum levels of thyroid hormones were investigated in vivo and discussed.

\section{Background}

The effects of GTE catechin on the rat thyroid were examined in a 2-, 4-, 8- and 13-week feeding studies. Commercially available polyphenols-60 (P-60) which contains green tea extract catechin at $66.2 \%$ was used as a source of catechins. A basic diet containing P-60 at 0 (Control), 0.625, $1.25,2.5$ and $5.0 \%$ were fed and goiters were observed in 13-week test. The mean thyroid weight of rats fed a diet containing $5.0 \%$ of P-60 (5.0\% group) significantly increased to $444 \%$ of the control in males and to $304 \%$ of the control in females. Histological examinations of the thyroid of the $5.0 \%$ group revealed marked hypertrophy and/or hyperplasia of the follicles, some with depletion of colloid and some with rich colloid, and formation of fibrous capsule. Slight hypertrophy of follicular cells was observed in male rats fed a diet containing $2.5 \%$ of $\mathrm{P}-60(2.5 \%$ group). The degree and incidence of thyroid lesions were higher in males than in females. These results indicate that dietary administration of the green tea extract catechin at high doses induced goitre in rats and this may be due to antithyroid effects of catechin ${ }^{10}$.

On the contrary, daily oral administration of standardized and defined green tea polyphenols to humans for 28 days was found to be safe ${ }^{11}$. In another dose-response study, dietary exposure of green tea catechin at levels upto $5 \%$ in a diet for 90 days to F344 rats resulted in no significant histopathological changes in the thyroid. Therefore, a detailed study on thyroid gland morphological / histological and functional changes in vivo after the exposure of GTE has been investigated. The effects of pure catechin on the thyroid were also studied to delineate whether the anti-thyroidal/goitrogenic effect of green tea extract are modified through catechin, the important flavonoids present in tea ${ }^{12}$.

\section{Green Tea used in the study}

Non-fermented green tea : produced by drying and steaming the fresh leaves to inactivate the polyphenol oxidase and thus, no oxidation occurs. The polyphenol content of green tea varies from $30 \%$ to $40 \%$ and $3 \%$ to $10 \%$ respectively ${ }^{13}$.

Green tea was collected from Institute of Himalayan Bioresource Technology (IHBT), Council of Scientific and Industrial Research, Palampur, Himachal Pradesh, India and the composition as mentioned by the producer (Table 1). 
Table I : Constituents of Green Tea

\begin{tabular}{lc}
\hline Constituents & Green Tea \\
\hline Epicatechin (EC) & $1.55 \%$ \\
Epigallo catechin gallate (EGCG) & $9.00 \%$ \\
Epicatechin gallate (ECG) & $4.80 \%$ \\
Epigallocatechin (EGC) & $5.00 \%$ \\
Caffeine & $2.38 \%$ \\
\hline
\end{tabular}

Preparation of Tea

Preparation of aqueous extract of green tea was done following the method of Wei et.al ${ }^{14}$. Briefly, $2.5 \mathrm{~g}$ tea (green) was added to $100 \mathrm{ml}$ of boiling water and was steeped for 15 minutes. The infusion was cooled to room temperature and then filtered. The tea leaves were extracted a second time with $100 \mathrm{ml}$ of boiling water and filtered and the two filtrates were combined to obtain different concentrations/doses.

\section{Doses of tea and oral feeding}

- Dose I / $1.25 \mathrm{~g} \%$ tea: $1.25 \mathrm{~g} \mathrm{GTE}$ as prepared made $100 \mathrm{ml}$ with water and the final extract fed to animals orally at a dose of $1 \mathrm{ml} / 100 \mathrm{~g}$ body weight. The dose was equivalent to 5 cups of tea /individual /day.

- Dose II/ 2.50g\% tea and Dose III/ 5.00g\% tea: by the same procedure $2.5 \mathrm{~g} \%$ and $5.00 \mathrm{~g} \%$ were prepared respectively and was fed to animals at a dose of $1 \mathrm{ml} / 100 \mathrm{~g}$ body weight. The II and III doses are equivalent to 10cups and 20 cups of tea /individual /day.

Freshly prepared tea extracts of different dilutions were fed to experimental animals of different groups respectively.

\section{Duration of the treatment}

The animals were administered the above mentioned 3 doses with GTE for the period of 30 days.

\section{Morphological/ Histological Changes}

The relative weight of thyroid gland increased significantly in a dose-dependant manner in both the GTE and pure catechin treated animals as compared to control group (Figure 1).

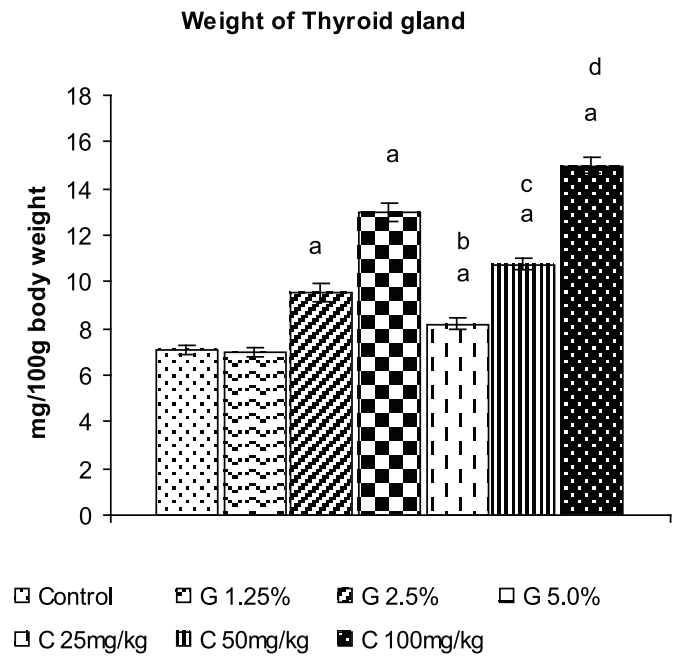

Figure 1: Alterations in the relative thyroid gland weight of rats subjected to green tea extract and catechin treatment. Each bar denotes mean $\pm \mathrm{SD}$, $\mathrm{n}=8$. One way analysis of variance (ANOVA) test followed by a multiple comparison $\mathrm{t}$ - test was performed. Mean values are significantly different by ANOVA at $\mathrm{p}<0.05$. ${ }^{\mathrm{a}}$ Control versus other groups; ${ }^{b}$ green tea $1.25 \mathrm{~g} \%$ versus catechin $25 \mathrm{mg} / \mathrm{kg}$; ${ }^{\mathrm{c}}$ green tea $2.5 \mathrm{~g} \%$ versus catechin $50 \mathrm{mg} / \mathrm{kg}$; ${ }^{\mathrm{d}}$ green tea $5.0 \mathrm{~g} \%$ versus catechin $100 \mathrm{mg} / \mathrm{kg}$. [Food \& Chemical Toxicology 48: 2304-2311]

The changes in weight are corroborated in the histological changes of the thyroid gland. Normal thyroid gland is made up of thyroid follicles formed by a single layer of low cuboidal epithelium. The nucleus of the follicular cell is round to ovoid, sometimes irregular in shape, centrally placed and uniform in size and inconspicuous. A basal lamina envelops the follicles. Numerous capillaries and lymphatics surround the follicles. The follicular lumen is occupied by colloid, partly composed of thyroglobulin which is evenly applied to the luminal cell borders ${ }^{15}$. Histological sections (E/ $\mathrm{H}$ stains) of thyroid of green tea and catechin induced groups are shown in Plates 1 and 2 respectively. 


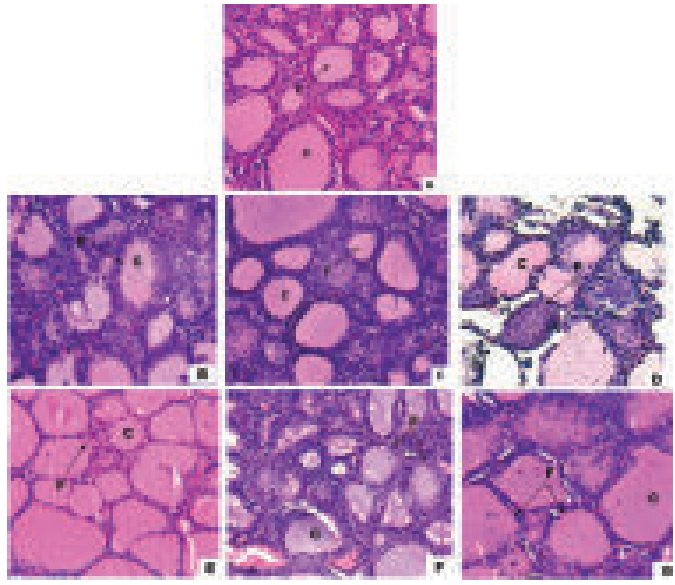

Plate1: Photomicrographs of paraffin-embedded $\mathrm{H} \& \mathrm{E}$ - stained rat thyroid sections. (A) Rat thyroid section (400X) from control animals. (B) Thyroid section (400X) from catechin treated animals (Dose I). (C) Thyroid section (400X) from catechin treated animals (Dose II). (D) Thyroid section $(400 \mathrm{X})$ from catechin treated animals (Dose III). (E) Thyroid section (400X) from green tea administered animals (Dose I). (F) Thyroid section (400X) from green tea administered animals (Dose II). (G) Representative thyroid section (400X) from green tea administered animals (Dose III). $\mathrm{C}=$ Colloid, $\mathrm{F}=$ Follicle of thyroid. [Food \& Chemical Toxicology 48: 2304 2311]

The histological features of thyroid glands of pure catechin and green tea extract treated groups of animals along with the control group of rats were shown in Plate 1 and 2. Thyroid gland section from control animals obviously showed no pathologic feature. Thyroid appeared normal both grossly and microscopically in $1.25 \mathrm{~g} \%$ dose of green tea treated group. But diffuse hypertrophy and /or hyperplasia of thyroid follicular epithelial cells without inflammatory reactions was found in the other treated groups. In the $5.0 \mathrm{~g} \%$ group of GTE, the number of thyroid follicles was increased and they were not uniform in shape and colloid content as most of the follicles were colloid rich however, colloid depleted follicles were also observed; while in

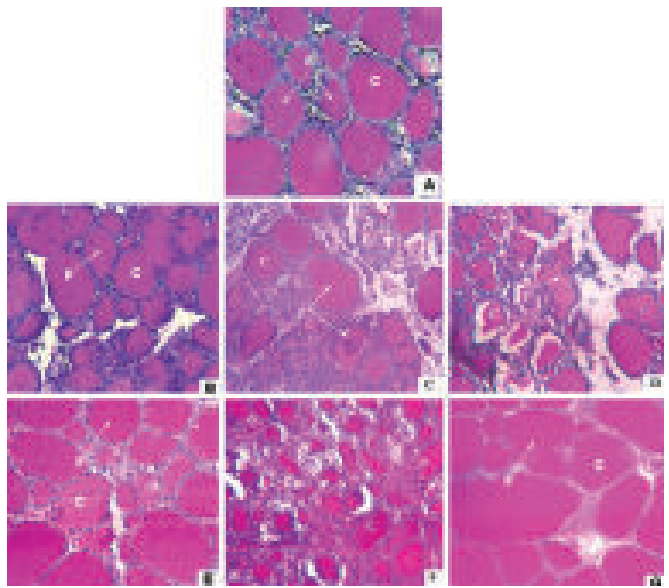

Plate 2: Photomicrographs of paraffin-embedded PAS- stained rat thyroid sections.. (A) Rat thyroid section (400X) from control animals. (B) Thyroid section (400X) from catechin treated animals (Dose I). (C) Thyroid section (400X) from catechin treated animals (Dose II). (D) Thyroid section $(400 \mathrm{X})$ from catechin treated animals (Dose III). (E) Thyroid section (400X) from green tea administered animals (Dose I). (F) Thyroid section (400X) from green tea administered animals (Dose II). (G) Representative thyroid section (400X) from green tea administered animals (Dose III). $\mathrm{C}=$ Colloid, $\mathrm{F}=$ Follicle of thyroid. [Food \& Chemical Toxicology 48: 2304 2311]

the $2.5 \mathrm{~g} \%$ group of GTE, the thyroid follicles were diffusely hypertrophic and contain little colloid with increased height of the follicular epithelium from cuboidal to tall columnar. Pure catechins treatment at a doses of $25 \mathrm{mg}$ and $50 \mathrm{mg} /$ $\mathrm{kg}$ body weight daily for same duration had produced thyroid lesions characterized by the presence of few follicles filled with depleted colloid and irregular shaped follicles having decreased luminal spaces with tall columnar or cuboidal follicular epithelium; while at a dose of $100 \mathrm{mg} / \mathrm{kg}$ body weight of pure catechin, the presence of desquamated epithelial cells and mononuclear cell infiltration within the follicles were observed. 
Goitre is a diffuse or nodular enlargement of the thyroid gland when there is deficiency of circulating thyroid hormone because of inborn errors of metabolism, iodine deficiency, or goitrogenic agents and if the hypothalamic pituitary axis is intact, production of thyroid stimulating hormone (TSH) is increased; consequently, cellular activity and increased glandular activity and glandular mass result in an attempt to restore the euthyroid state. Worldwide the most common cause of thyroid hormone deficiency is an inadequate amount of iodine in the diet, leading to iodine deficiency goitre $^{16}$. Other causes include inborn errors of thyroid metabolism (dishormonogenic goitre), dietary goitrogens and goitrogenic drugs and chemicals. The pathologic changes of simple non-toxic goitre include (a) hyperplasia (b) colloid accumulation and (c) nodularity ${ }^{16-18}$.

Hyperplasia represents the response of thyroid to TSH, other growth factors or circulating stimulatory antibodies ${ }^{19}$. The hyperplasia may compensate by thyroid hormone deficiency. If the deficiency of thyroid hormone occurs at birth or early in life, cretinism or juvenile myoxedema may result, even though the gland is enlarged and hyperplastic. In hyperplastic gland, the epithelium is tall and columnar; the follicles are collapsed and contain only scanty colloid. Thyroid follicles may not remain in state of continuous hyperplasia but instead undergo involution, with the hyperplastic follicles reaccumulating colloid. The epithelium becomes low cuboidal or flattened and resembles that of the normal gland. Some follicles become much larger than normal, contain extensive colloid and are lined with flat epithelium (overinvolution; exhaustion atrophy). The gland is diffusely enlarged, soft and has glistening cut surface because of the excess of stored colloid. In addition to large follicles filled with colloids, there are foci in the gland where hyperplasia is still evident. This phase of non-toxic goitre is termed as colloid goitre ${ }^{15}$.
After oral administration of green tea the weight of thyroid gland increases in a dose-dependant manner i.e. maximum after the consumption of $5 \mathrm{gm} \%$ (a" 20 cups/day) followed by $2.5 \mathrm{gm} \%$ (a"10 cups/day) and least after $1.25 \mathrm{gm} \%$ (a"5 cups/ day). Hypertrophy and hyperplasia of the thyroid follicular cells are found after prolonged consumption of both the moderate and high doses of green tea. The findings are almost consistent with the plants foods as found in radish, bamboo shoot, cassava etc. ${ }^{20-22}$ In $2.5 \%$ green tea fed group (a"10cups of tea), thyroid follicles are diffusely hyperplastic, irregularly shaped, lined with enlarged cuboidal or columnar epithelium with depleted colloid, whereas at a dose of $5.0 \%$ (a"20 cups of tea), colloid rich follicles with flat epithelial cell and mononuclear cell infiltration. All these observations reveals that consumption of green tea at moderate and high doses (a"10cups or a"20cups/day) develop a morphological state as resembled in goitrous population in environmentally iodine deficient or dietary goitrogen exposed population.

\section{Functional Changes of Thyroid Gland}

Thyroid gland synthesizes thyroid hormones (thyroxine and tri-iodo-thyronine) followed by its storage and release in response to demand of the body. The biosynthesis of thyroid hormone requires highly regulated steps catalyzed by a number of enzymes. In earlier studies it was demonstrated that high consumption of flavonoids diminishes thyroid iodide uptake and thyroid peroxidase (TPO) activity, inducing enlargement and histological changes in the thyroid ${ }^{5,23,24}$. A Brazilian medicinal herb that is known to contain flavonoids ${ }^{25}$, causes inhibition in in vitro TPO activity and scavenges $\mathrm{H}_{2} \mathrm{O}_{2}$, an essential TPO co-factor ${ }^{26}$. Green tea is a rich source of flavonoids and the effects of green tea extracts in the activities of major thyroid hormone synthesizing enzymes in relation to pure catechin are described as following. 


\section{Thyroidal $\mathrm{Na}^{+}-\mathrm{K}^{+}$ATPase}

It is a membrane-spanning protein complex responsible for extrusion of $\mathrm{Na}^{+}$and absorption of $\mathrm{K}^{+}$by most animal cells, including follicular epithelium of thyroid gland. Iodine required for hormone synthesis accumulates within the gland through the combined actions of Na-K ATPase and $\mathrm{Na}^{+}, \mathrm{I}^{-}$contraporter ${ }^{27}$. The activity level of thyroidal $\mathrm{Na}^{+}-\mathrm{K}^{+}$ATPase following the method of Esmann ${ }^{28}$ at different doses of green and catechin are shown.

Thyroidal $\mathrm{Na}^{+}-\mathrm{K}^{+}$ATPase activity of both the GTE and catechin treated groups of animals was increased in a dose-dependent manner in comparison to that control group. $\mathrm{Na}^{+}-\mathrm{K}^{+}$ATPase activity increased $27.5 \%$ and $69.8 \%$ at the doses of $2.5 \mathrm{~g} \%$ and $5.0 \mathrm{~g} \%$ GTE group of animals respectively whereas, $17.3 \%, 34.6 \%$ and $87.8 \%$ increment were found after the administration of $25 \mathrm{mg}, 50 \mathrm{mg}$ and $100 \mathrm{mg}$ pure catechin respectively. However, no change in the activity of $\mathrm{Na}, \mathrm{K}+$ ATPase was observed in $1.25 \mathrm{~g} \%$ green tea treated group (Figure 2).

The iodide is concentrated in the follicular cells by an active transport mechanism, the so-called 'Sodium-Iodide Symporter' (NIS) that is energy consuming, connected to a $\mathrm{Na}^{+}-\mathrm{K}^{+}$ATPase activity and stimulated by TSH. NIS-mediated iodide transport is inhibited by the $\mathrm{Na}^{+}-\mathrm{K}^{+}$ ATPase inhibitor ouabain as well as by the competitive inhibitors thiocyanate and perchlorate ${ }^{29} \cdot \mathrm{Na}^{+}-\mathrm{K}^{+}$ATPase is composed of two subunits in equimolar ratios. These are the á subunit with molecular mass of $\sim 113 \mathrm{kDa}$ and the smaller glycosylated â subunit with a protein portion accounting for $35 \mathrm{kDa}$ of the overall molecular mass of $55 \mathrm{kDa}$. Isoforms exists for á (á $\mathfrak{a}_{1}, \mathrm{a}_{2}$ and $\left.\mathrm{a}_{3}\right)$ and $\mathrm{a}\left(\hat{\mathrm{a}}_{1}, \hat{\mathrm{a}}_{2}\right.$ and $\left.\hat{\mathrm{a}}_{3}\right)$ subunits. Hypothyroidism increases the number of $\mathrm{Na}^{+}$$\mathrm{K}^{+}$ATPase subunits $\left(\mathrm{a}_{1}\right.$ and $\hat{\mathrm{a}}_{1}$ ) in rat thyroid gland ${ }^{30}$. Increased $\mathrm{Na}^{+}-\mathrm{K}^{+}$ATPase activity as observed perhaps for the development of a morphological as well as biochemical hypothyroidism under the influence of flavonoids (catechin) present in tea. Active transport of
Thyroidal Na,K+ATPase Activity

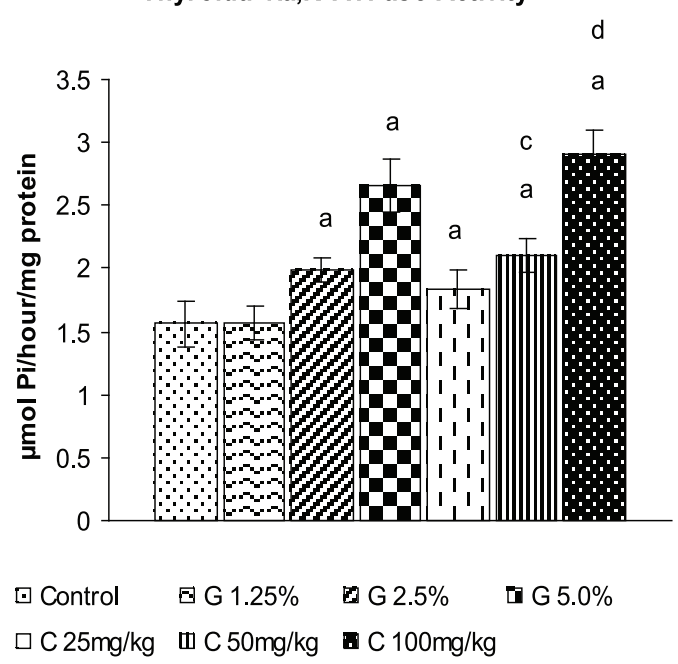

Figure 2: Effect of green tea extract and pure catechin on the activity of thyroidal $\mathrm{Na}, \mathrm{K}+$ ATPase. Each bar denotes mean \pm SD of three pooled samples. Each pool containing a mixture of three thyroid glands isolated from three individual rats. The assay was repeated twice. One way analysis of variance (ANOVA) test followed by a multiple comparison t- test was performed. Mean values are significantly different by ANOVA at $\mathrm{p}<0.05^{\mathrm{a}}$ Control versus other groups; ' green tea $2.5 \mathrm{~g} \%$ versus catechin $50 \mathrm{mg} /$ $\mathrm{kg} ;{ }^{\mathrm{d}}$ green tea $5.0 \mathrm{~g} \%$ versus catechin $100 \mathrm{mg} / \mathrm{kg}$. [Food \& Chemical Toxicology 48: 2304-2311]

iodide into the thyroid gland is a crucial and ratelimiting step in the biosynthesis of thyroid hormones which play an important role in the metabolism, growth and maturation of a variety of organ systems ${ }^{31} \cdot \mathrm{Na}^{+} / \mathrm{I}$ " symporter (NIS) is a key plasma membrane protein that catalyzes the active accumulation of iodide (I") in the thyroid gland; co transports two sodium ions along with one iodide ion, with the transmembrane sodium gradient serving as the driving force for iodide uptake. The sodium gradient, providing the energy for this transfer, is generated by the ouabain- sensitive $\mathrm{Na}^{+}-\mathrm{K}^{+}$ATPase. $\mathrm{Na}^{+}$$\mathrm{K}^{+}$ATPase activity was increased markedly in the experimental animals treated with in this study 
pure catechins and GTE respectively. Increased $\mathrm{Na}^{+}-\mathrm{K}^{+}$ATPase activities as observed is for the development of a morphological as well as biochemical hypothyroidism under the influences of catechins present in the green tea.

\section{Thyroid Peroxidase (TPO)}

Iodide must be oxidized to a high oxidation state, a state that is dependent on the presence of $\mathrm{H}_{2} \mathrm{O}_{2}$ and is catalyzed by thyroid peroxidase (TPO). TPO is a glycoprotein having a prosthetic heme group located in the apical membrane. The enzyme is also essential for incorporation of iodine into tyrosine residues in thyroglobulin for organification and coupling of the iodotyrosines to form T4 and T3.

The human TPO gene is located on chromosome 2 pterp12, spans about $150 \mathrm{~kb}$. The full length human TPO cDNA encodes a protein of 933 amino acids $^{32}$. The amino terminus of TPO is located in the lumen of thyroid follicles, and the extra cellular domains forms a loop created by two intermolecular disulphide bonds which is by a single membrane spanning domain in close proximity to its carboxy terminus ${ }^{33}$. While the prosthetic heme group, a bis-hydroxylated heme that is distinct from the heme $b$ (protoporphyrin IX) found in many other hemoproteins, is covalently bound to glutathione 399 and aspertate 238 of the apoprotein ${ }^{34}$. The activity of TPO is increased by TSH in vivo ${ }^{35}$, and this stimulatory effect is the consequence of increase synthesis of TPO ${ }^{36}$. TSH and other stimulators of cyclic AMP signaling pathway increase TPO mRNA abundance in cultured thyroid cells ${ }^{37}$.

The synthesis of thyroid hormones is the major function of the thyroid gland and the main regulatory enzyme for the thyroid hormone biosynthesis is thyroid peroxidase as mentioned. In the present study, thyroid peroxidase (TPO) activity of all the experimental groups except $1.25 \mathrm{~g} \%$ GTE treated group was decreased significantly in comparison to that of the control group. TPO activity was decreased $33.1 \%$ and
$53.6 \%$ respectively at doses of $2.5 \mathrm{~g} \%$ and $5.0 \mathrm{~g} \%$ GTE treated groups whereas, $14.8 \%, 50.4 \%$ and $82.6 \%$ inhibition were found at the doses $25 \mathrm{mg}$, $50 \mathrm{mg}$ and $100 \mathrm{mg}$ of pure catechin treated groups (Figure 3).

\section{Thyroid Peroxidase Activity}

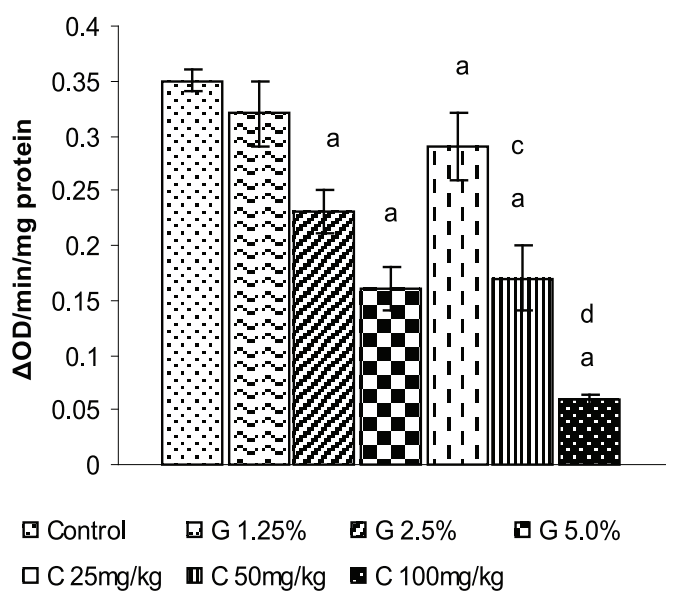

Figure 3: Effect of green tea extract and catechin on the activity of thyroid peroxidase (TPO) at different doses. Each bar denotes mean \pm SD of three pooled samples. Each pool containing a mixture of three thyroid glands isolated from three individual rats. The assay was repeated twice. One way analysis of variance (ANOVA) test followed by a multiple comparison t- test was performed. Mean values are significantly different by ANOVA at $\mathrm{p}<0.05^{\mathrm{a}}$ Control versus other groups; ' green tea $2.5 \mathrm{~g} \%$ versus catechin $50 \mathrm{mg} /$ $\mathrm{kg}$; ${ }^{\mathrm{d}}$ green tea $5.0 \mathrm{~g} \%$ versus catechin $100 \mathrm{mg} / \mathrm{kg}$. [Food \& Chemical Toxicology 48: 2304-2311]

It is known that a wide variety of environmental substances including foods can induce goiters in rats ${ }^{20-22}$. Most of these goitrogenic substances directly interfere with synthesis or secretion of thyroid hormones by various mechanisms, such as blockage of iodine uptake by the thyroid, organification defect due to inhibition of thyroid peroxidase (TPO) and blockage of thyroid hormone release. The reduction in serum levels of thyroid hormones induces an elevation of 
serum levels of TSH and consequently results in hypertrophy and/or hyperplasia of follicular cells ${ }^{10}$.

In consistent with above observations both the GTE and pure catechin exposure decreased the activities of thyroid peroxidase (TPO) in a dose dependent manner. Thyroid peroxidase (TPO), a heme-containing enzyme is found in the apical membrane of thyroid follicular cells, that catalyzes the thyroid hormone biosynthesis i.e. oxidation of inorganic iodide (I-) to reactive iodine (I) for binding iodine to tyrosyl residues in thyroglobulin. Divi and Doerge ${ }^{38}$ conducted a structure-activity study of 13 commonly consumed flavonoids and reported that most flavonoids were potent inhibitors of TPO and catechins were also showed the inhibitory effect on TPO activity ${ }^{39}$. Studies by Divi and Doerge ${ }^{38}$ showed that genistein, quercetin, kaempferol and naringenin inhibit thyroxine synthesis by acting as alternate substrates for tyrosine iodination, yielding mono, di and tri-iodo-isoflavones. These compounds were also shown to irreversibly inhibit thyroid peroxidase. A probable mechanism of action may relate to the ability of phenolic compounds with a free resorcinol (metahydrophenol) moiety to inhibit TPO. Therefore, the proposed mechanism of action for enzyme inhibition as found involves the conversion of thyroid peroxidase to a free radical that reacts with resorcinol moiety and produces a flavonoid radical. The flavonoid radical could covalently bind to the catalytic amino acid residues on the enzyme, leading to enzyme inactivation. Through their inhibitory activity on thyroid peroxidase, they can cause elevated thyroid stimulating hormone levels, which promote thyroid gland growth and thyroid dysfunction ${ }^{40}$.

\section{5'-Monodeiodinase I}

The main product of thyroid gland is tetraiodothyroinine (T4) - a pro hormone that must be activated by deiodination to triiodothyronine (T3) in order to initiate thyroid action. The deiodination reaction occurs in the phenolic ring or outer ring of the $\mathrm{T} 4$ molecule and is catalyzed by the two tissue specific deiodinase, type 1 (D1) and type 2 (D2). On the other hand, T4 and T3 can be irreversibly inactivated by deiodination of their tyrosil ring (inner ring deiodination), a reaction catalyzed by either D1 or type 3 deiodinase (D3), the third member of the deiodinase group. Therefore, the deiodinase have the capacity to terminate thyroid hormone action ${ }^{41}$.

The three deiodinase protein (D1, D2 and D3) are structurally similar (- $50 \%$ sequence identity). All are the integral membrane proteins of $29-30 \mathrm{kd}$ and they are similar in the region surrounding the active catalytic centre ${ }^{42-44}$. All the three deiodinases have a single transmembrane segment, present near the $\mathrm{N}$ - terminus, D1 has small amino terminal extension in the extracellular space, while D2 has in the lumen of the endoplasmic reticulum, and a single transmembrane domain existing the membrane at about position $40^{45}, 46$. As a result the active centre of both D1 and D2 are in the cytosol. D3 has also the integral membrane protein, but its orientation is opposite, so that its active centre is in the extracellular space.

GTE and catechin treatment caused a statistically significant inhibition in the activity of 5'-deiodinase I (5'-DI) over the control value. 5 '-DI activity was decreased $27.6 \%$ and $62.2 \%$ at dose of $2.5 \mathrm{~g} \%$ and $5.0 \mathrm{~g} \%$ GTE groups respectively whereas, $20.3 \%, 40.3 \%$ and $70.3 \%$ inhibition were found at the doses $25 \mathrm{mg}, 50 \mathrm{mg}$ and $100 \mathrm{mg}$ of pure catechin treated groups respectively. However, no such significant changes were observed in the animals treated with green tea at the dose of $1.25 \mathrm{~g} \%$ for 30 days (Figure 4). 


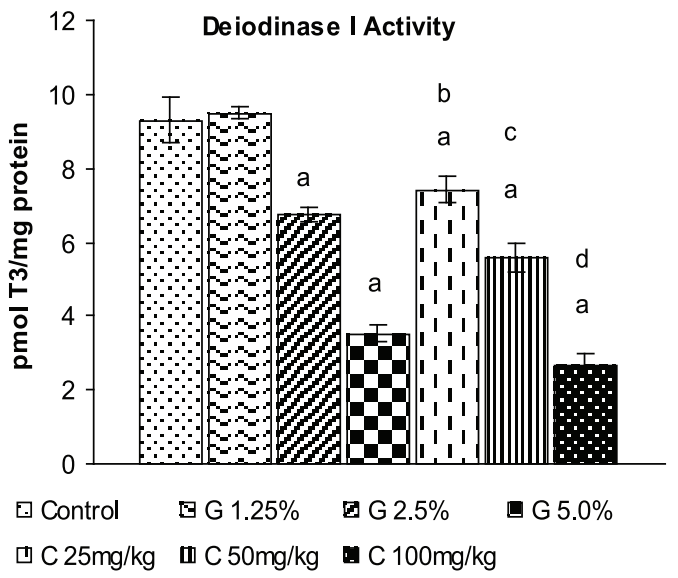

Figure 4: Effect of green tea extract and catechin on the activity of thyroid 5'-Deiodinase I (5'-DI). Each bar denotes mean \pm SD of three pooled samples. Each pool containing a mixture of three thyroid glands isolated from three individual rats. The assay was repeated twice. One way analysis of variance (ANOVA) test followed by a multiple comparison t- test was performed. Mean values are significantly different by ANOVA at $\mathrm{p}<0.05^{\text {a }}$ Control versus other groups; ${ }^{b}$ green tea $1.25 \mathrm{~g} \%$ versus catechin $25 \mathrm{mg} / \mathrm{kg}$; ${ }^{\mathrm{c}}$ green tea $2.5 \mathrm{~g} \%$ versus catechin $50 \mathrm{mg} / \mathrm{kg} ;{ }^{\mathrm{d}}$ green tea $5.0 \mathrm{~g} \%$ versus catechin $100 \mathrm{mg} / \mathrm{kg}$. [Food \& Chemical Toxicology 48: 2304-2311].

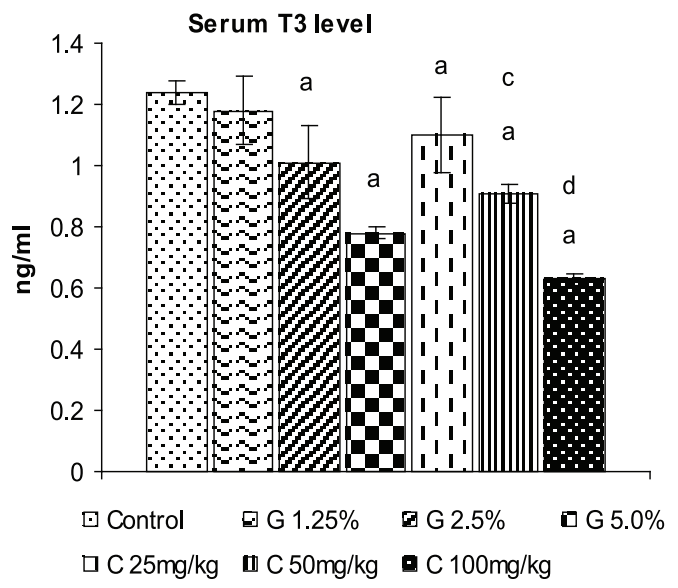

Furthermore, green tea as well as pure catechin exposure had significantly reduced the activity of 5'-monodeiodinase I (5'-DI) in thyroid gland which suggested that green tea catechin decreased the rate of conversion of T4 into T3. $5 '$-DI is a member of a group of selenoenzymes that metabolize thyroid hormone and thus modulate thyroid hormone action. 5'-DI predominantly found in the liver, kidney and thyroid and responsible for generating most of the circulating T3. 5'-DI can catalyze both activation of $\mathrm{T} 4$ by outer-ring deiodination and inactivation of $\mathrm{T} 4$ by inner-ring deiodination to produce $\mathrm{rT} 3^{47}$. Previously, in experimental animals, it has been described that the high consumption of flavonoids including catechin diminished the enzymatic activity of 5'-DI in vivo as well as in vitro study ${ }^{48}$. The result of the present study confirms the earlier findings.

\section{Thyroid hormone profiles}

Serum T4 and T3 levels were significantly decreased in GTE group at $5.0 \mathrm{~g} \%$ dose than the $2.5 \mathrm{~g} \%$ dose as compared to control group of rats. However, the mean serum $\mathrm{T} 3$ and $\mathrm{T} 4$ levels were significantly lower both in $50 \mathrm{mg}$ and 100 $\mathrm{mg} / \mathrm{kg}$ catechin treated groups in comparison to

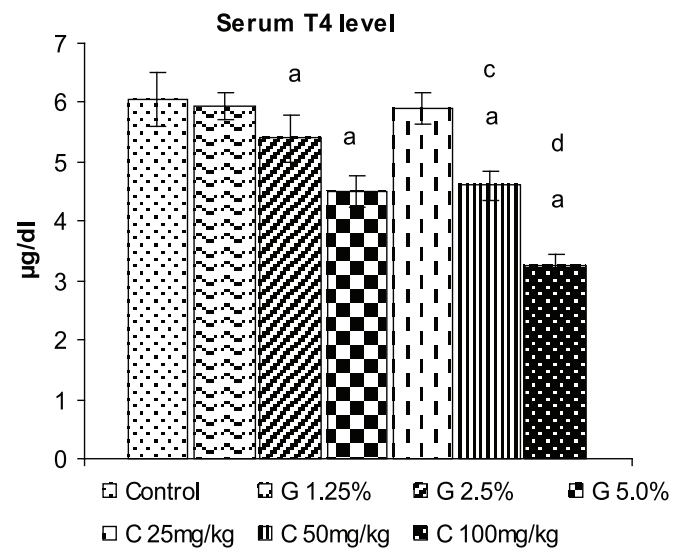

Figure 5: Effect of green tea extract and catechin on serum $\mathrm{T} 3$ and $\mathrm{T} 4$ level. Each bar denotes mean $\pm \mathrm{SD}, \mathrm{n}=8$. One way analysis of variance (ANOVA) test followed by a multiple comparison $\mathrm{t}$ - test was performed. Mean values are significantly different by ANOVA at $\mathrm{p}<0.05 .{ }^{\mathrm{a}}$ Control versus other groups; ${ }^{\mathrm{c}}$ green tea $2.5 \mathrm{~g} \%$ versus catechin $50 \mathrm{mg} / \mathrm{kg} ;{ }^{\mathrm{d}}$ green tea $5.0 \mathrm{~g} \%$ versus catechin $100 \mathrm{mg} / \mathrm{kg}$. [Food \& Chemical Toxicology 48: 2304-2311]. 
control group (Figure 5) while serum thyrotrophic hormone (TSH) level was significantly increased in both the GTE treated group at high doses over the control values, however, pure catechin significantly enhanced the serum TSH level in $25 \mathrm{mg}, 50 \mathrm{mg}$ and $100 \mathrm{mg} / \mathrm{kg}$ catechin treated groups in comparison to control group (Figure 6).

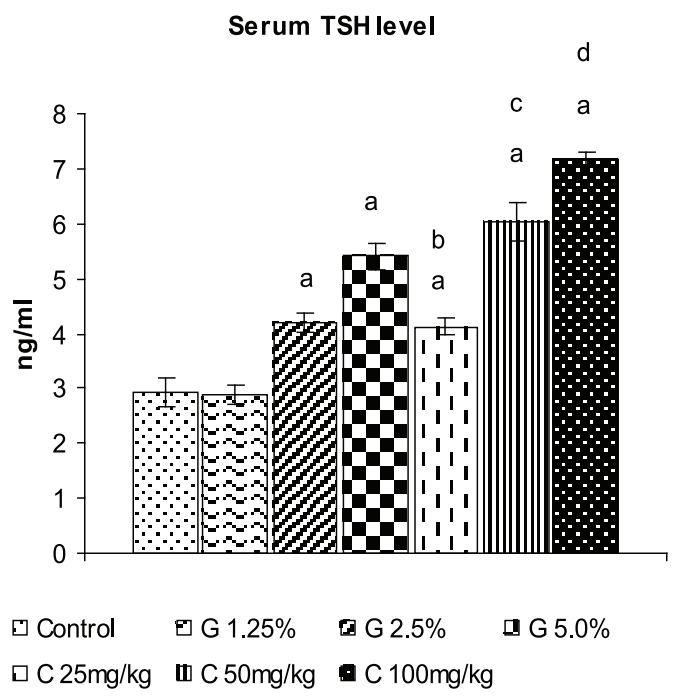

Figure 6: Effect of green tea extract and pure catechin on serum TSH level. Each bar denotes mean $\pm \mathrm{SD}, \mathrm{n}=8$. One way analysis of variance (ANOVA) test followed by a multiple comparison t- test was performed. Mean values are significantly different by ANOVA at $\mathrm{p}<0.05$. ${ }^{\mathrm{a}}$ Control versus other groups; ${ }^{b}$ green tea $1.25 \mathrm{~g} \%$ versus catechin $25 \mathrm{mg} / \mathrm{kg}$; ${ }^{c}$ green tea $2.5 \mathrm{~g} \%$ versus catechin $50 \mathrm{mg} / \mathrm{kg}$; ${ }^{\mathrm{d}}$ green tea $5.0 \mathrm{~g} \%$ versus catechin $100 \mathrm{mg} / \mathrm{kg}$. [Food \& Chemical Toxicology 48: 2304-2311].

Follicular cells of the thyroid are designed for hormone synthesis and secretion. T3 and T4 are the predominant circulating thyroid hormones synthesized and secreted by follicular cells. T3 is considered as a biologically active thyroid hormone and most of the circulating T3 is generated by extra-thyroidal deiodination of T4, taking place mainly in the liver. Serum levels of thyroid hormones, including T3, T4 and TSH, are commonly used as reliable indicators of the thyroid function in humans and experimental animals. Changes in the serum concentration of these hormones can reflect disturbances in their glandular synthesis and/or secretion as well as disorders in their extra-thyroidal peripheral metabolism. In the present study, serum T3 and T4 levels were significantly decreased with elevated TSH level in both treated groups of animal. Due to exposure of GTE and catechin, the resulting hypothyroidism causes increased pituitary production of TSH in an attempt to stimulate thyroid to correct the deficiency of thyroid hormones.

\section{Conclusion}

GTE at relatively high doses caused hypothyroidism in rats by altering morphological and functional status of thyroid. Moreover, the commercially available catechins have shown pronounced effect inducing hypothyroidism which validates that the effect of GTE may be due to antithyroidal or goitrogenic effect of catechins present in tea. All these suggest that catechin present in green tea has the antithyroidal as well as goitrogenic potential and its regular consumption at relatively high doses pose a threat to the functioning of thyroid.

\section{Acknowledgement:}

This study was partly supported by National Tea Research Foundation (NTRF), Kolkata 700001

\section{Author affiliations}

1. *Amar K Chandra,Professor, Endocrinology and Reproductive Physiology Laboratory, Department of Physiology, University College of Science \& Technology, University of Calcutta, 92, Acharya Prafulla Chandra Road, Kolkata-700009, India. email: physiology.ac@gmail.com; amarkchandra @rediffmail.com. Phones : +91332350 8386 Extn. (223) [Office]; +913323553838 [Residence]; +91 9433161840 [Cell Phone] Fax : 91-033 23519755 / 91-03322413222 / 91-03322413222

2. Neela De, Post-Doc Fellow, Department of Physiology, University College of Science \& Technology, University of Calcutta, Kolkata.

*For correspondance 


\section{References}

1. Graham HN. Green tea compostion, consumption, and ployphenol chemistry, Prev Med 1992; 21: 334-350.

2. Koo MWL, Cho CH. Pharmacological effects of Green tea on the gastrointestinal system. Eur J Pharmacol 2004; 500: 177-185.

3. Mukhtar H, Khan N. Tea polyphenols for health promotion-Mini review, Life Sciences. 2007; 81: 519-533.

4. McKay DL, Blumberg JB. The role of tea in human health: An update, J Am Coll Nutr 2002; 21: 2002113.

5. Lindsay RH, Gaitan E, Cooksey R. Pharmacokinetics and intra-thyroidal effects of flavonoids. In "Environmental goitrogenesis" (Gaitan, E., Ed.), CRC Press Bocu. Roton, FL 1989; pp. 43-56.

6. Gaitan E, Lindsay RH, Reichert RD, Ingbar SH, Cooksey RC, Legan $J$, Meydrech EF, Hill $J$, Kubota K. Antithyroid and goitrogenic effects of millet: Role of C-Glycosylflavones. J Clin Endocrinol Metabol 1989; 68: 707-714.

7. Sartelet, H, Serghat S, Lobstein A, Ingenbleek Y, Anton R, Petitfrere E, Aguie-Aguie G, Martiny L, Haye B. Flavonoids extracted from Fonio millet (Digitaria exilis) reveal potent antithyroid properties. Nutrition 1996; 12: 100-106.

8. Khelifi-Touhami F, Taha RA, Badary OA, Lezzar A, Hamada FM. Goitrogenic activity of p-Coumaric acid in rats. J Biochem Mol Toxicol 2003; 17: 324-328.

9. Ferreira ACF, Neto JC, da Silva ACM, Kuster RM, Carvalho SDP. Inhibition of thyroid peroxidase by Myrcia uniflora flavonoids. Chem Res Toxicol 2006; 19: 351-355.

10. Sakamoto, Y, Mikuriya H, Tayama K, Takahashi H, Nagasawa A, Yano N, Yuzawa K, Ogata A, Aoki N. Goitrogenic effects of green tea extract catechins by dietary administration in rats. Arch Toxicol 2001; 75: 591-596.

11. Chow HH, Cai Y, Hakim IA, Crowell JA, Shahi F, Brooks CA, Dorr RT, Hara Y, Alberts DS. Pharmacokinetics and safety of green tea polyphenols after multiple-dose administration of epigallocatechin gallate and polyphenon $\mathrm{E}$ in healthy individuals. Clin Cancer Res. 2003; 9: 33123319.
12. Chandra AK, and De N. Goitrogenic/antithyroidal potential of green tea extract in relation to catechin in rats. Food and Chem Toxicol 2010; 48: 2304 2311.

13. Cabrera C, Artacho R, Gime'nez, R. Beneficial Effects of Green Tea - A Review, J Am Coll Nutr. 2006; 25: 79-99.

14. Wei H, Zhang X, Zhao JF, Wang ZY, Bickers D, Labwohl M. Scavenging of hydrogen peroxide and inhibition of ultraviolet light-induced oxidative DNA damage by aqueous extracts from green and black teas. Free Radic Biol Med 1999; 26: 14271435 .

15. Baloch, Z.W., and Livolsi, V.A.. Pathology. In "Werner and Ingbar's the Thyroid", (L.E. Braverman and R.D. Utiger,Ed.) $9^{\text {th }}$ Edition,. Lippincott Williams and Wilkins, Philadelphia, 2005; pp 422-449.

16. Doniach I. The Thyroid gland. In: Systemic pathology. (Symmers W SrC, ed.) $2^{\text {nd }}$ ed. Edinburgh, Churchil Livingston 1978: pp 1976.

17. Studer H, Ramelli I. Simple goiter and its variations: euthyroid and hyperthyroid multinodular goiter. Endocr Rev 1982; 3: 40-61.

18. Taylor S. The evaluation of nodular goiter. J Clin Endocrinol Metab 1953; 13(10): 1232-1247.

19. Van der Gaag RD, Drexhage HA, Wiersinga WM. Further studies on thyroid growth- stimulating immunoglobulins in euthyroid nonendemic goiter. J Clin Endocrinol Metab 1984; 60: 972-979.

20. Chandra AK, Mukhopadhyay S, Ghosh D, Tripathy S. Effect of radish (Raphanus sativus Linn.) on thyroid status under conditions of varying iodine intake in rats. Ind J Exp Biol. 2006; 44: 653-661.

21. Chandra AK, Ghosh D, Mukhopadhyay S, Tripathy S. Effect of bamboo shoot, Bambusa arundinacea (Retz.) Willd. on thyroid status under conditions of varying iodine intake in rats. Indian J Exp Biol. 2004; 42: 781-86.

22. Chandra AK, Ghosh D, Mukhopadhyay S, Tripathy S. Effect of cassava (Manihot esculenta Crantz) on thyroid status under conditions of varying iodine intake in rats. African J Traditional Complementary and Alternative Medicines 2006a; 3: 87-99.

23. Moudgal NR, Raghupathy E, Sarma PS. Studies on goitrogenic agents in food III goitrogenic actions of some glycosides isolated from edible nuts. Journal of Nutrition 1958; 66: 291-300. 
24. Cody V, Kochria J, Hesch RD. Structure-activity relationships of flavonoids as inhibitors of iodothyronine deiodinase. In "Environmental goitrogenesis, F1" (Gaitan E Ed.), CRC Press, Boca Raton 1989; pp 7-69. .

25. Rossi-Bergmann, B, Costa S, Moraes V. Brazilian medical plants: A rich source of immunomodulatory substance, Ciencia with culture. J Braz Assoc Adv Sci 1997; 49: 395-401.

26. Ferreira ACF, Rosenthal D, Carvalho DP. Thyroid peroxidase inhibition by Kalanchoe brasiliensis aqueous extract. Food Chem Toxicol. 2000; 38: 417-421.

27. Dai G, Levy O, Carrasco N. Cloning and characterization of the thyroid iodide symporter. Nature 1996; 379: 458-460.

28. Esmann M. ATPase and phosphate activity of $\mathrm{Na}+-$ $\mathrm{K}+$-ATPase: Molar and specific activity, protein determination. Methods Enzymol 1988; 156: 105115 .

29. Spitzweg C, Morris JC. Sodium Iodide Symporter (NIS) and Thyroid. Hormones 2002; 1: 22-34.

30. Le Grow, AB, Fielding DC, Pressley TA. Stimulation of $\mathrm{Na}^{+}, \mathrm{K}+$-ATPase by hypothyroidism in the thyroid gland. J Endocrino 1999; 160: 453-460.

31. Carrasco N. Iodide transport in the thyroid gland. Biochim. Biophys. Acta 1993; 1154: 65-82.

32. Kimura S, Kotani T, McBride OW, Umeki K, Hirai K, Nakayama T, Ohtaki S. Human Thyroid Peroxidase: Complete cDNA and Protein Sequence Chromosome mapping, an identification of two alternate spliced mRNAs. Proc. Natl Acad Sci USA. 1987; 84: 5555- 5559.

33. Taurog A, Dorris ML, Yokoyama N, Slauter C. Purification and characterization of a large, tryptic fragment of human thyroid peroxidase with high catalytic activity. Arch Biochem Biophys 1990; 278: $333-341$.

34. Taurog A, Wall M. Proximal and distal histidines in thyroid peroxidase: Relation to the alternative spliced form. TPO-2. Thyroid. 1998; 8:185-191.

35. Nagataki S, Uchimura H, Masuyama Y, Nakao K. Thyrotropin and thyroidal peroxidase activity. Endocrinology 1973; 92: 363-371.

36. Nigasaka A, Hadaka H. Quantitative modulation of thyroid iodide peroxidase by thyroid stimulating hormone. Biochem Biophys Res Commun 1980; 96: 1143-1149.
37. Chazenbalk G, Magnusson, RP, Rapoport B. Thyrotropin stimulation on cultured thyroid cells increases steady state levels of the messenger ribonucleic acid for thyroid peroxidase. Mol Cell Endocrinol. 1987; 60: 239-244.

38. Divi RL, Doerge DR. Inhibition of thyroid peroxidase by dietary flavonoids. Chem Res Toxicol. 1996; 9:16-23.

39. Satoh K, Sakamoto Y, Ogata A, Nagai F, Mikuriya $\mathrm{H}$, Numazawa M, Tayama K, Aoki N. Inhibition of aromatase activity by green tea extract catechins and their endocrinological effects of oral administration in rats. Food Chem Toxicol 2002; 40: 925-933.

40. Skibola CF, Smith MT. Potential health impacts of excessive flavonoid intake. Free Radical Bio Med. 2000; 29: 375-383.

41. Bianco AC, Salvatore D, Gereben B, Berry MJ, Larsen PR. Biochemistry, cellular and molecular biology and physiological roles of the iodothyronine selenodeiodinases. Endocr Rev. 2002; 23: 38-89.

42. Berry MJ, Keiffer JD, Harney JW. Selenocysteine confers the biochemical properties of the type I iodo-thyronine deiodinase. J Biol Chem. 1991; 266: 14155-8.

43. Croteau W, Whittemore SL, Schneider MJ, Germain DLS. Cloning and expression of cDNA for a mammalian Type II iodothyronine deiodinase. J Biol Chem. 1995; 270 (28): 16569-16575.

44. Buettner, C., Harney, J.W., Larsen, P.R. The role of selenocysteine 133 in catalysis of human type 2 iodothyronine deiodinase. Endocrinology 2000; 141: 4606-4612.

45. Toyoda N, Berry MJ, Harney JW, Larsen PR. Topological analysis of the integral membrane protein, type I deiodinase (DI). J Biol Chem. 1995; 170: $12310-12318$.

46. Baqui MM, Geren B, Harney JW, Larsen PR, Bianco AC. Distinct subcellular localization of transiently expressed type I and type II iodo-thyronine deiodinase as determined by immunofluroscence confocal microscopy. Endocrinology 141, 2000; 4309- 4312 .

47. Köhrle J. Local activation and inactivation of thyroid hormones: the deiodinase family. Mol Cell Endocrinol 1999; 151: 103-119.

48. Ferreira AC, Lisboa PC, Oliveira KJ, Lima LP, Barros IA, Carvalho DP. Inhibition of thyroid type 1 deiodinase activity by flavonoids. Food Chem Toxicol 2002; 40: 913-917. 